Comparison of Recommended SFAT Model Predictions With Measurements Made Using the Improved SFAT

November 1994

RECEIVED

MAY 151996

OSTI

UNITED STATES PROGRAM FOR TECHNICAL ASSISTANCE TO IAEA SAFEGUARDS

DEPST TMENT OH ENIERGY

BEPAART IUEN IT OF STSATE

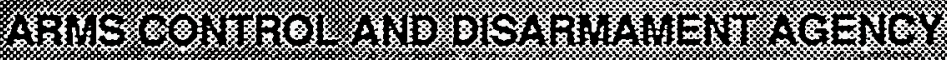

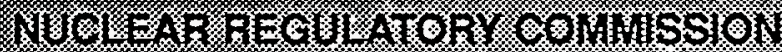

OEP ATIMENT OF DEFEUSE-

Prepared for

The International Atomic Energy

Agency

Department of Safeguards

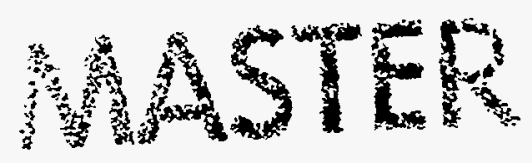


This report was prepared as an account of work sponsored by ån Agency of the United States Government. Neither the United States nor the United States Department of Energy, nor any of their employees, nor any of their contractors, subcontractors, or their employees, makes any warranty, express or implied, or assume any legal liability or responsibility for the accuracy, completeness, or usefulness of any information, apparatus, product, or process disclosed, or represents that its use would not infringe privately owned rights. Further, neither the subject matter nor the content of this report reflects any policy, expressed of implied, by the United States Government. 


\title{
Comparison of Recommended SFAT Model Predictions with Measurements Made Using the Improved SFAT
}

\author{
by \\ Thomas W. Laub and Stephen A. Dupree \\ Sandia National Laboratories \\ P.O. Box 5800 \\ Albuquerque, New Mexico 87185
}

\begin{abstract}
Design alternatives for the International Atomic Energy Agency's Spent Fuel Attribute Tester (SFAT) were evaluated using radiation transport calculations. Several design changes were recommended and implemented in a new SFAT device. The new SFAT was tested on September 8 and 9, 1993, at the Industrial Power Company, Ltd. intermediate spent fuel storage facility in Olkiluoto, Finland. The new SFAT performed very well. The results of the tests are compared with predictions made during the SFAT optimization study.
\end{abstract}




\section{Comparison of Recommended SFAT Model Predictions with Measurements Made Using the Improved SFAT}

\section{Introduction}

The International Atomic Energy Agency (IAEA) Spent Fuel Attribute Tester (SFAT) is designed to allow the detection of ${ }^{137} \mathrm{Cs}$ photons from a target spent fuel assembly amid the high background from surrounding spent fuel assemblies. The ${ }^{137} \mathrm{Cs}$ fission product was chosen as the spent fuel indicator because it is the longest-lived of the fission products with a clearly identifiable signature photon. Therefore, ${ }^{137} \mathrm{Cs}$ could be used to identify both short-cooled and long-cooled spent fuel. During two previous studies, ${ }^{1,2}$ computer calculations were performed to evaluate proposed design improvements in the SFAT: These studies resulted in several recommendations for design modifications. These were:

(1) Provide collimator pipes in several lengths: $200 \mathrm{~cm}, 150 \mathrm{~cm}, 125 \mathrm{~cm}$, and $100 \mathrm{~cm}$ (the $150-\mathrm{cm}$ pipe was the preferred length),

(2) Make the pipe walls as thick as possible within weight and handling constraints,

(3) Use low-Z filters in place of the lead filters (iron is preferred) and move filters away from detector crystal,

(4) Reduce the lower shielding,

(5) Increase shielding surrounding the crystal and photomultiplier tube.

(6) Replace the 2-inch diameter $\mathrm{NaI}(\mathrm{Tl})$ crystal with a narrower crystal, perhaps a 1.5inch diameter crystal, and

(7) Choose the length of the $\mathrm{NaI}$ crystal based on economic criteria but no shorter than 1 inch.

With the exception of multiple collimator pipe lengths, all of these recommendations were implemented in the new SFAT. The collimator pipe length was fixed at about $150 \mathrm{~cm}$ and the pipe wall thickness was increased to $6 \mathrm{~mm}$. Iron filters were used and placed away from the $\mathrm{NaI}$ crystal. The size of the NaI crystal was reduced to 1.5 inches diameter by 1.5 inches long; although, there is still room for a 2- by 2-inch crystal. The lower shielding was reduced and a stainless steel, water-tight container around the entire device provided increased shielding around the crystal. Figure 1 (provided by Tarvainen et al. ${ }^{3}$ ) shows the collimator geometry of the new SFAT as-built. The final parameters of the SFAT collimator system were based on experimental results. ${ }^{4}$

There were actually two tasks related to the development of the new SFAT. The task assigned to SNL was to optimize the measurement geometry of the SFAT using computational methods. The task of designing and manufacturing the new SFAT was assigned to the Finnish Support Programme to IAEA Safeguards. During the design of the new SFAT several new features were added. These included an ultrasonic positioning system using a telescoping mechanism (housed in the stainless steel, water-tight container), and collision and leakage switches. In addition, the new SFAT was optimized for inspection use. The positioning system allowed extremely accurate 
positioning of the collimator pipe. The new SFAT in its stainless steel container with the positioning system is shown in Figure 2 (provided by Tarvainen et al. ${ }^{3}$ ).

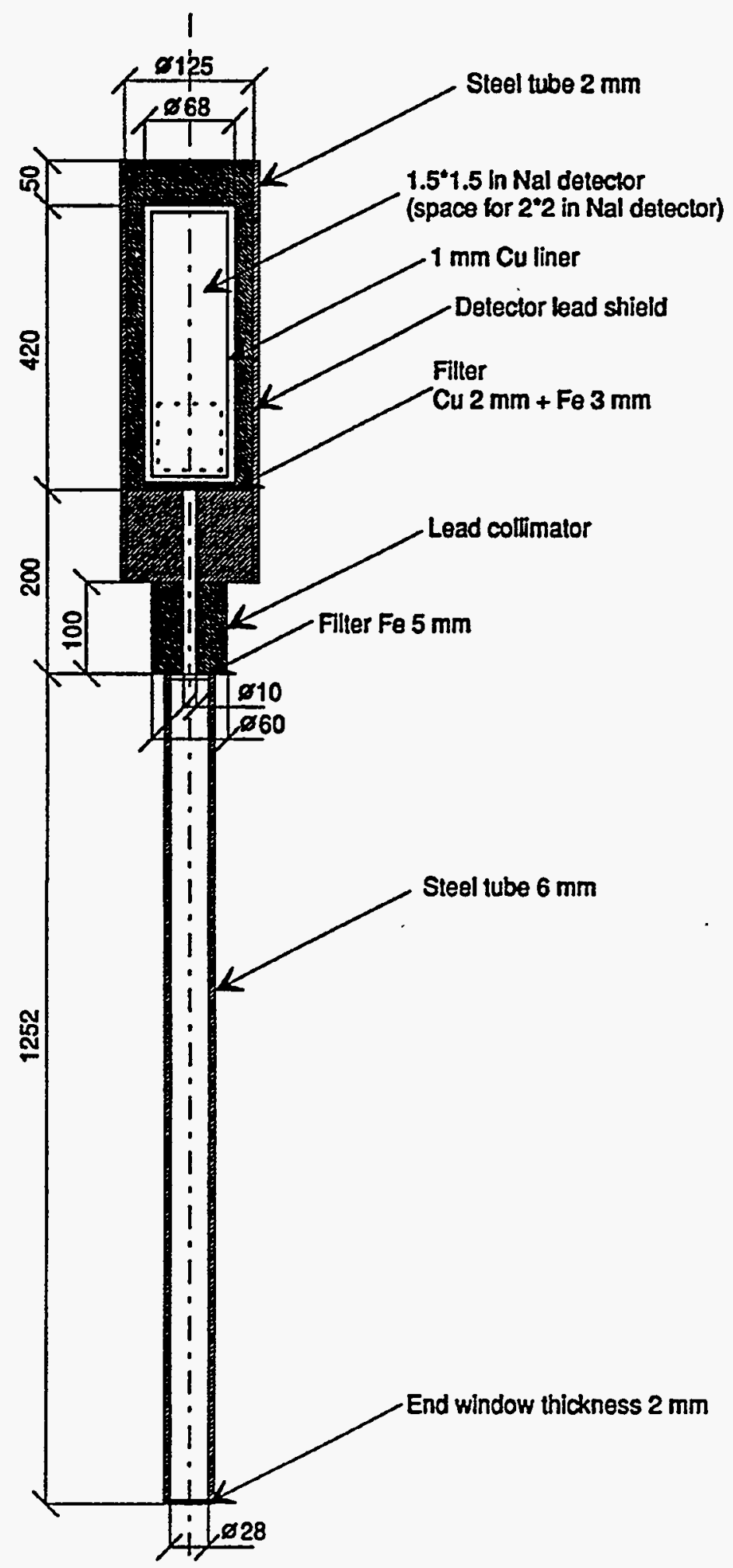

Figure 1. The new SFAT as-built. 


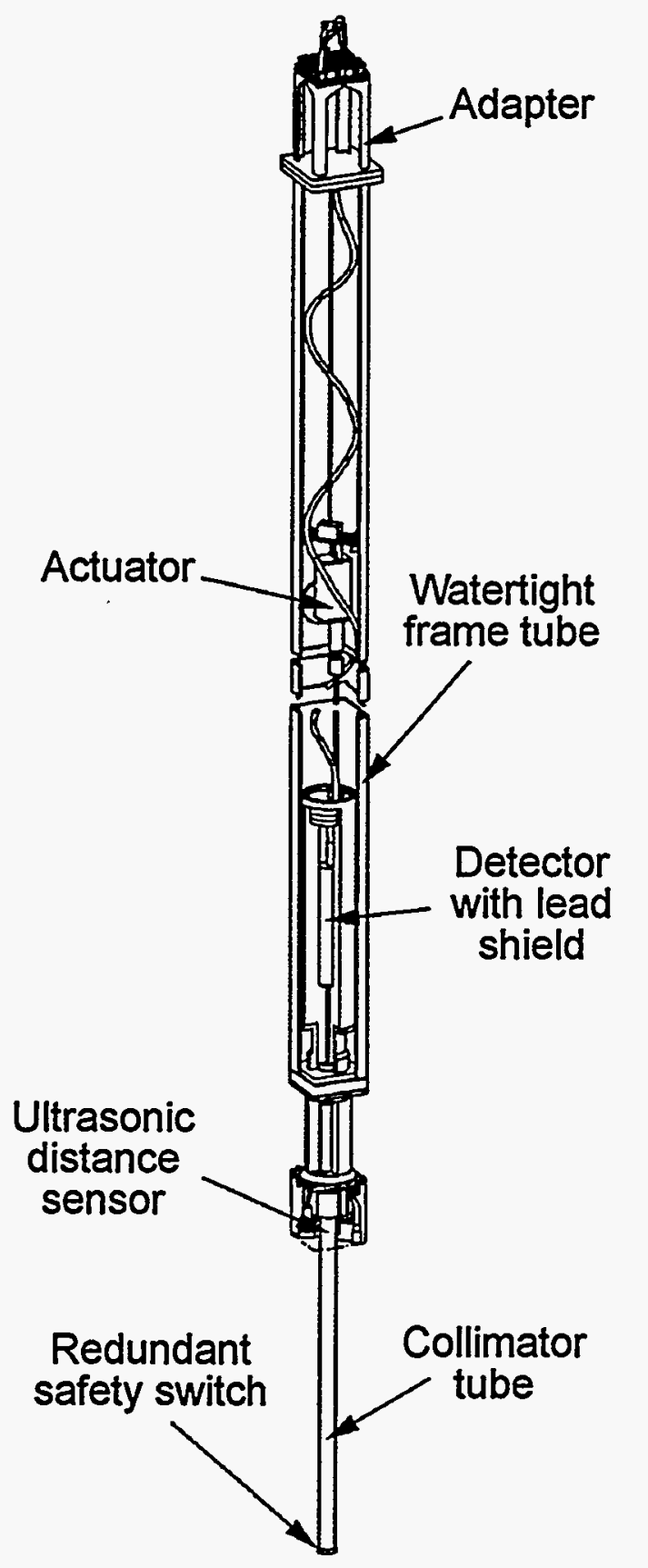

Figure 2. The new SFAT in its stainless steel container with the telescoping mechanism and ultrasonic positioning system.

During the measurements, the IAEA used an upgraded Multi-Channel Analyzer that contained high-count-rate electronics. The high-count-rate electronics compensated for the high radiation level near the spent fuel assemblies resulting in reduced detector deadtime and eliminating pile-up effects. In previous measurements, pile-up effects were evident. ${ }^{2}$ 
The previous modeling efforts by Sandia National Laboratories (SNL) assumed a target spent fuel assembly source with a burnup of $27.5 \mathrm{MWd} / \mathrm{kgU}$ and a cooling time of 5 years. The calculations also considered a background source consisting of an infinite array of spent fuel assemblies located in the storage rack around the target assembly, each with $27.5 \mathrm{MWd} / \mathrm{kgU}$ burnup and a 5-year cooling time. A target spent fuel assembly source with a burnup of $27.5 \mathrm{MWd} / \mathrm{kgU}$ and a cooling time of 10 years, surrounded by the same 5-year-cooled background assemblies, was also considered.

\section{Previous Measurements}

Previous measurements made using the first SFAT device were performed at the Industrial Power Company, Ltd. (TVO) intermediate spent fuel storage facility (KPA-STORE) at Olkiluoto, Finland. ${ }^{6}$ Through the courtesy and cooperation of the Finnish Centre for Radiation and Nuclear Safety and the IAEA Department of Safeguards (Division of Development and Technical Support), the results of these measurements were made available to SNL for use in the SFAT modeling efforts. For completeness, some of the results of those measurements are reproduced here along with results of SNL's original SFAT model (Figures 3 through 6).

Figures 3 and 4 show measured and calculated background spectra. The measurement was obtained by suspending the SFAT over a gap between adjacent spent fuel assemblies such that no radiation source was in the line of sight of the instrument collimator. The calculation shows the background spectrum from all assemblies when the SFAT is not suspended over a target assembly. ${ }^{2}$ The high-energy tail (above about $1400 \mathrm{keV}$ or above channel 128) that is evident in Figures 3 through 6 is due to pile-up.

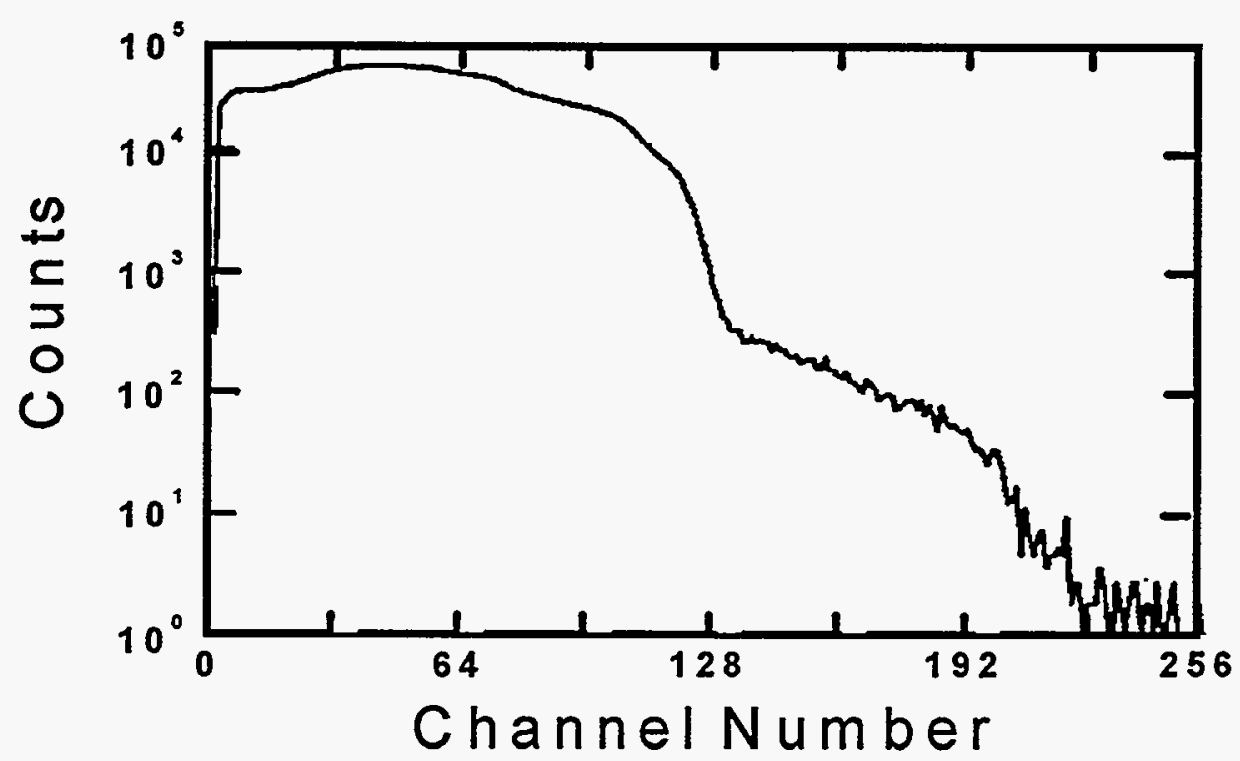

Figure 3. Pulse-height spectrum for a gap between spent fuel assemblies measured using the original SFAT. 
Figures 5 and 6 show measured and calculated spectra for the original SFAT over a long-cooled target assembly surrounded by short-cooled background assemblies. Notice also that in Figures 5 and $6 \mathrm{no}{ }^{137} \mathrm{Cs}$ photopeak is evident. Figure 5 is taken from Ref. 5 and is a measurement of relatively "cool" spent fuel assembly with $16 \mathrm{MWd} / \mathrm{kgU}$ and 7 years cooling time. However, in the same reference is a figure of a measurement of a "hot" spent fuel assembly with $32 \mathrm{MWd} / \mathrm{kgU}$ and 9 month cooling time that also does not show a ${ }^{137} \mathrm{Cs}$ photopeak. Reference 5 does not state the measurement time; however, a total count rate of 3700 counts per second is stated for the "cool" spent fuel assembly measurement. Therefore, using Figure 5, we estimate a count time of about 10 minutes for these measurements.

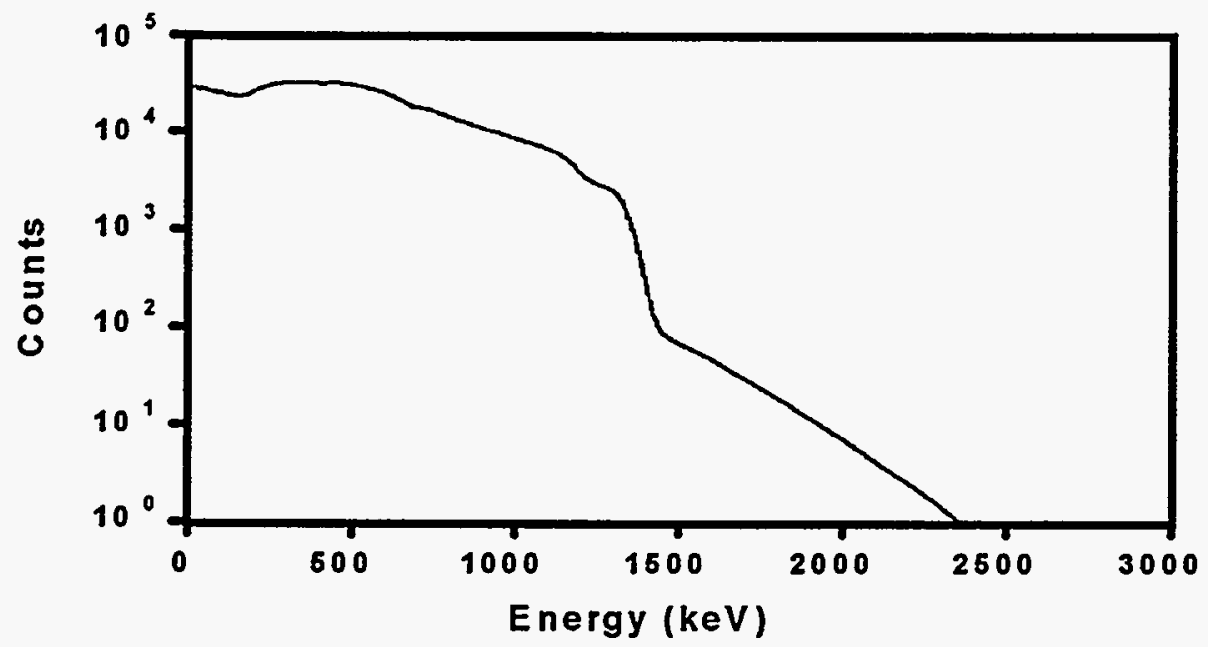

Figure 4. Pulse-height spectrum for the background source corresponding to a gap between spent fuel assemblies calculated using the original SFAT model and a standard $2 \times 2$ inch NaI(TI) response function.

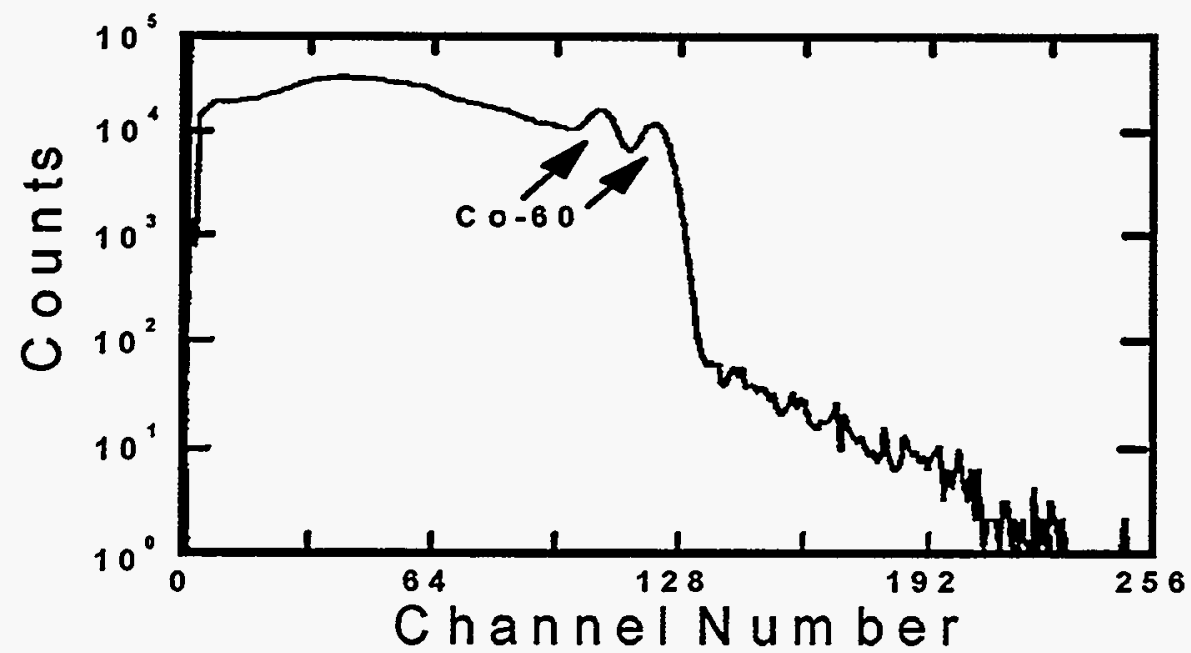

Figure 5. Pulse-height spectrum for a BWR spent fuel assembly with $16 \mathrm{MWd} / \mathrm{kgU}$ burnup and 7 years cooling time measured using the original SFAT. 


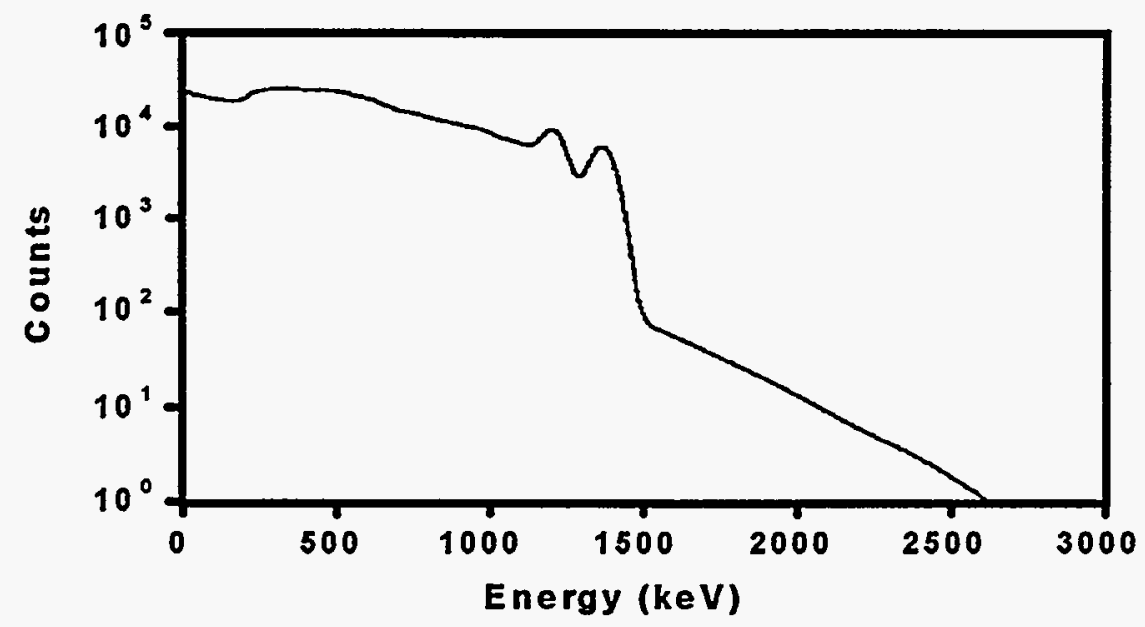

Figure 6. Pulse-height spectrum for the combined background and target fuel assembly sources corresponding to a $\mathrm{BWR}$ spent fuel assembly with $27.5 \mathrm{MWd} / \mathrm{kgU}$ and 5 years cooling time calculated using the original SFAT model and a standard $2 \times 2$ inch $\mathrm{NaI}(\mathrm{Tl})$ response function.

\section{Predictions for the Recommended SFAT Design}

After evaluating design alternatives and recommending design changes, calculations were performed to predict the response of the modified instrument. Pulse-height spectra predictions were made for 5-year-old and 10-year-old, $27.5 \mathrm{MWd} / \mathrm{kgU}$ spent fuel assemblies surrounded by 5 -year-old, $27.5 \mathrm{MWd} / \mathrm{kgU}$ background assemblies. These predictions are reproduced here (from Ref. 2) as Figures 7 and 8. The pulse-height spectra were produced using SNL software called GADRAS $^{6}$ that produces gamma detector response functions. These response functions can be optimized for a specific detector if calibration measurements are available. In this case calibration data were not available; therefore, a standard $\mathrm{NaI}$ detector response function for a 2-inchdiameter by 2 -inch-long crystal was used. The predictions indicate that a ${ }^{137} \mathrm{Cs}$ photopeak will be visible. In addition, the ${ }^{137} \mathrm{Cs}$ peak for the 10 -year-cooled assembly is more pronounced than for the 5-year-cooled assembly. This is because the ${ }^{137} \mathrm{Cs}$ has a longer half-life (30.2 years) than the other gamma-producing fission products or the activation product ${ }^{\circ} \mathrm{Co}$. Pile-up effects are also visible in Figures 7 and 8 . The pile-up effects are due to the high count rate and were used in the calculated pulse-height spectra because they were present in the initial measurements.

\section{New SFAT Measurements}

Fabrication of the modified SFAT, under the Finnish Support Programme, was completed in early 1993. On September 8 and 9, 1993, at the TVO KPA-STORE in Olkiluoto, Finland, the new SFAT was tested. The tests were performed by Rolf Arlt of the IAEA, Matti Tarvainen of the Finnish Centre for Radiation and Nuclear Safety (STUK), and Antero Tiitta of the Technical Research Centre of Finland (VTT) Reactor Laboratory. TVO personnel assisted by operating facility machinery and by providing access to the KPA-STORE. About sixty measurements were taken. In addition, measurements were made of ${ }^{137} \mathrm{Cs}$ and ${ }^{60} \mathrm{Co}$ calibration sources in air. These sources have a reference date of December 1, 1987, with strengths of $11.54 \mu \mathrm{Ci}$ and $11.82 \mu \mathrm{Ci}$ for the ${ }^{137} \mathrm{Cs}$ and ${ }^{60} \mathrm{Co}$ sources, respectively. Their strengths on September 9, 1993, are $10.12 \mu$ 
$\mathrm{Ci}$ for the ${ }^{137} \mathrm{Cs}$ and $5.59 \mu \mathrm{Ci}$ for the ${ }^{60} \mathrm{Co}$. Using the ${ }^{137} \mathrm{Cs}$ and ${ }^{60} \mathrm{Co}$ measurements, a detector response function was developed that was appropriate for new the SFAT detector.

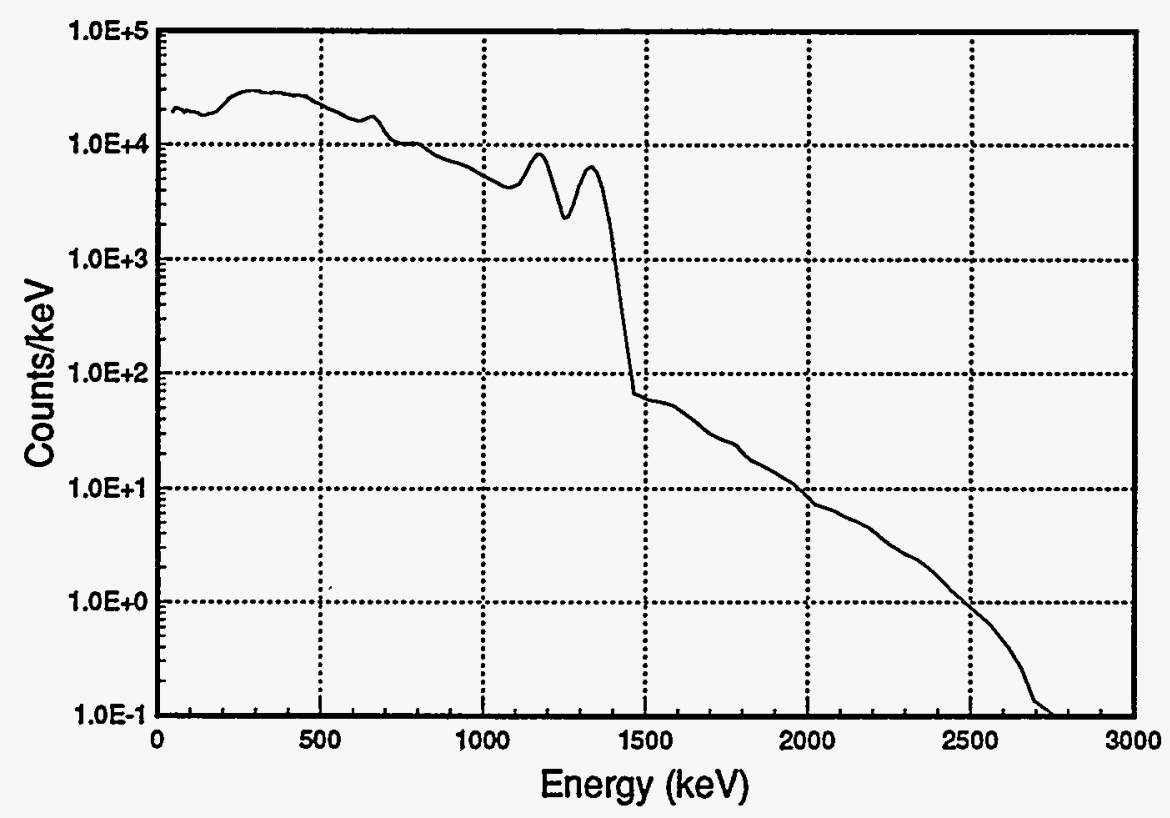

Figure 7. Predicted pulse-height spectrum for a 5-year-old, 27.5-MWd/kgU target assembly surrounded by 5-yearold, 27.5-MWd/kgU background assemblies using the recommended SFAT model and a standard $2 \times 2$ inch $\mathrm{NaI}(\mathrm{Tl})$ detector response function.

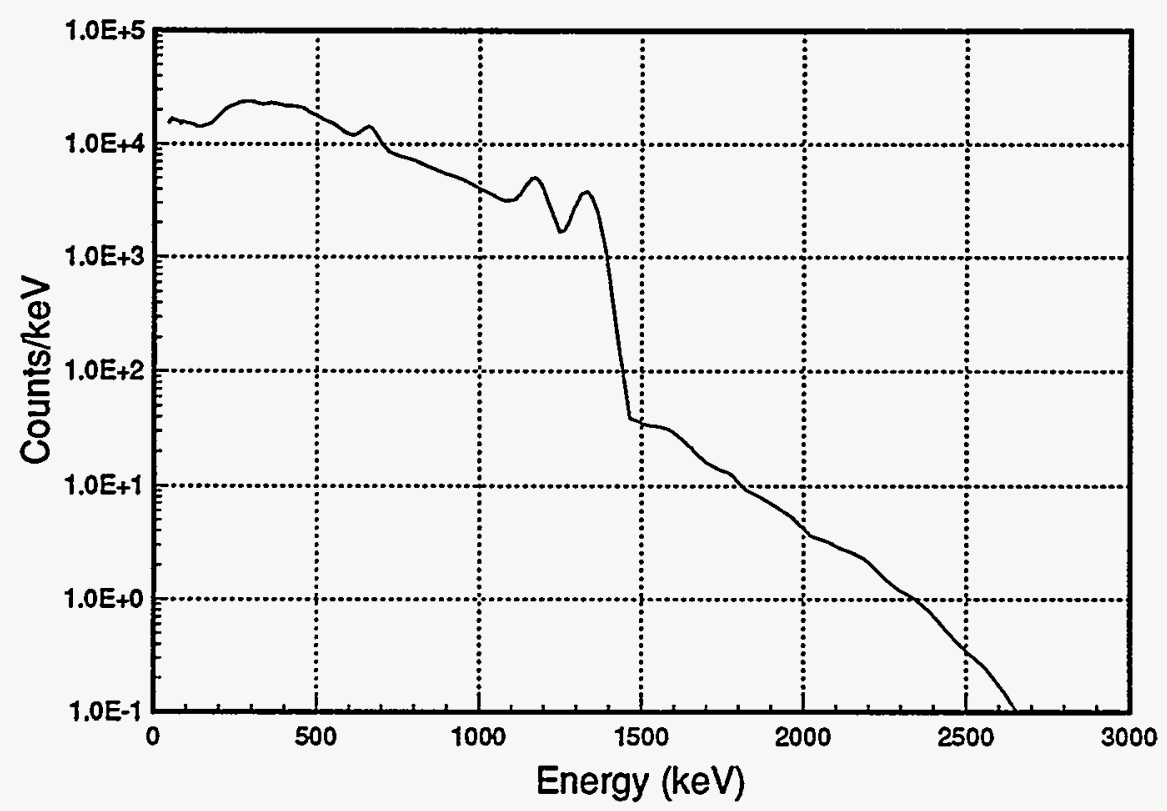

Figure 8. Predicted pulse-height spectrum for a 10-year-old, 27.5-MWd/kgU target assembly surrounded by 5year-old, 27.5-MWd/kgU background assemblies using the recommended SFAT model and a standard $2 \times 2$ inch $\mathrm{NaI}(\mathrm{Tl})$ detector response function.

Figure 9 shows a comparison of the measured calibration source pulse-height spectrum with a similar spectrum calculated using the detector response function. Note that a linear scale is used now where a semi-log scale was used in the preceding figures. The linear scale emphasizes the 
differences between the measured and the calculated pulse-height spectra. The energy scale is from $300 \mathrm{keV}$ to $1500 \mathrm{keV}$ because there was a low level discriminator setting of about $400 \mathrm{keV}$ used during the measurements.

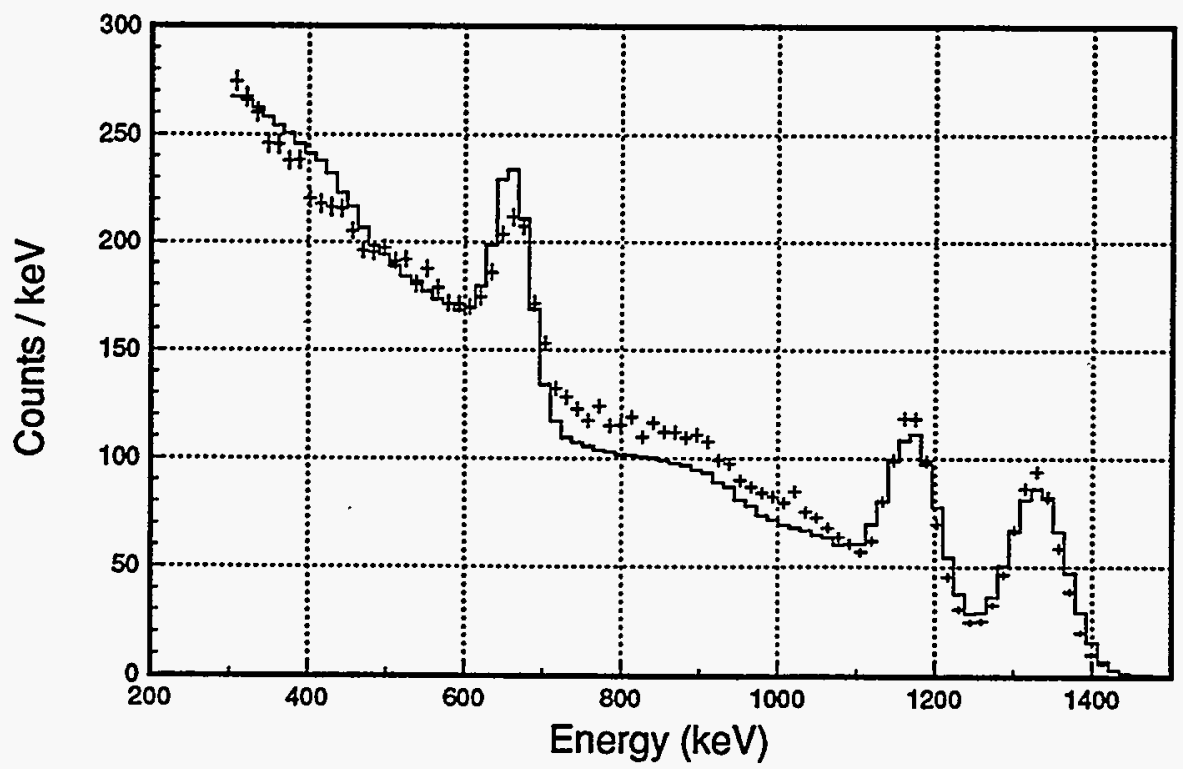

Figure 9. Comparison of measured calibration source pulse-height spectrum with one calculated using the detector response function. Error bars are the measured data.

During measurements, shifts in the energy calibration of the detector are not unusual. With the GADRAS software, it is possible to correct for these shifts without changing the other characteristics of the detector response. There was a shift in the energy calibration of the detector during the time between the measurement of the calibration sources and the measurement of spent fuel assemblies. Using the corrected new response function, the pulse-height spectra in Figures 7 and 8 have been recalculated from the original transport calculation results. Among the measurements made during the testing of the new SFAT, there was one assembly that had a burnup of $28 \mathrm{MWd} / \mathrm{kgU}$ and a cooling time of 5 years. This measurement is an excellent candidate to compare with the calculated target assembly of $27.5 \mathrm{MWd} / \mathrm{kgU}$ and 5 years cooling. A comparison of these measured and predicted pulse-height spectra is shown in Figure 10.

In Figure 10, the ${ }^{60} \mathrm{Co}$ peaks match the measurement quite well. The predicted ${ }^{137} \mathrm{Cs}$ peak is more pronounced than the measured ${ }^{137} \mathrm{Cs}$ peak. Also, at energies below $660 \mathrm{keV}$ the measurement exhibits significantly more multiple-scattered continuum photons than were predicted. This difference is probably caused by the detector response function. The measurements do not exhibit pile-up effects; therefore, the magnitude of the calculated response was scaled such that no pileup effects were produced by the detector response function. Note that the measurement time is only 200 seconds as compared to the estimated 10 -minute measurements made with the first SFAT.

The other calculated target assembly had a $27.5-\mathrm{MWd} / \mathrm{kgU}$ burnup and a 10 -year cooling time. There were no measurements of such long-cooled assemblies with high burnup because none existed in the KPA-STORE. The oldest reactor that contributes spent fuel to the KPA-STORE is 
only 12 years old. Therefore, assemblies that have a cooling time longer than 8 years did not spend a full 4 cycles in the reactor and did not achieve high burnup. The assembly measurement chosen to compare with the 10-year-old target assembly calculation had a burnup of 18 $\mathrm{MWd} / \mathrm{kgU}$ and an 8-year cooling time. Figure 11 shows this comparison. Again the ${ }^{60} \mathrm{Co}$ peaks match well. The magnitude of the ${ }^{137} \mathrm{Cs}$ peak also matches well. Again there is an underestimate of low-energy, multiple-scattered photons in the calculation. Given the differences between the burnup and cooling times of the measured and calculated target assembly, the agreement is very good.

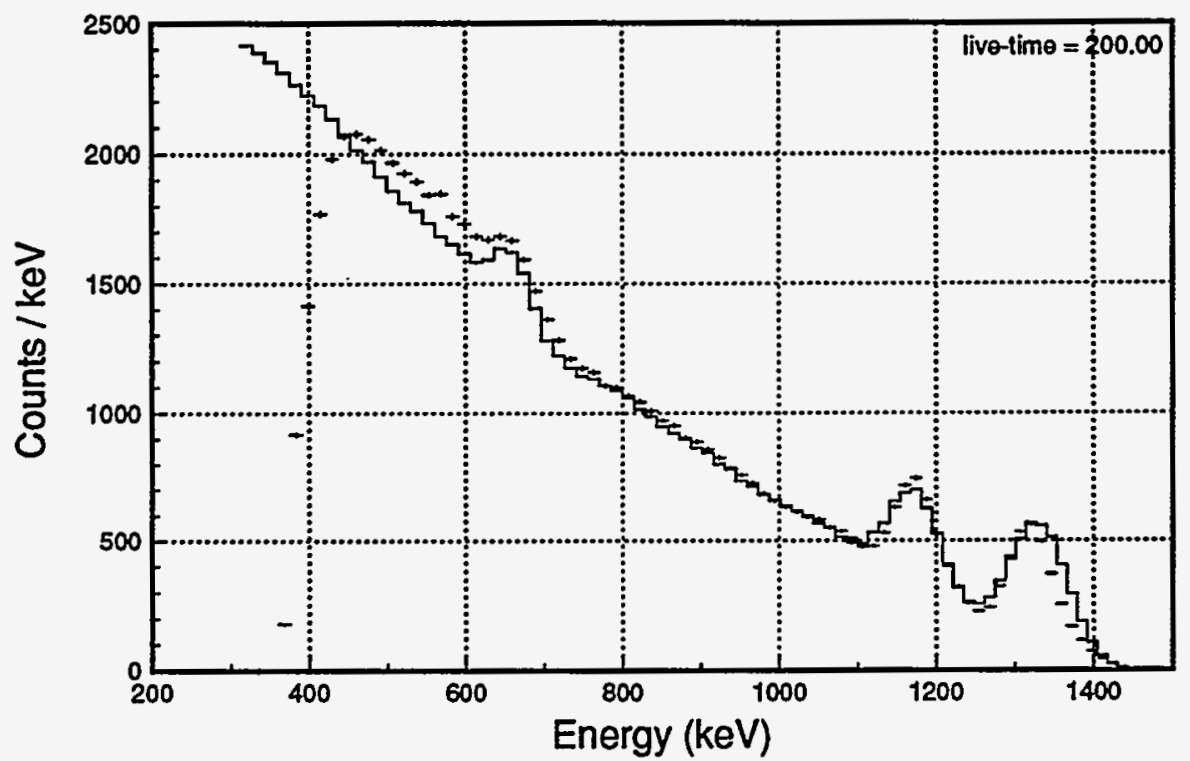

Figure 10. Comparison of a measured pulse-height spectrum from a 28-MWd/kgU, 5-years-old spent fuel assembly surrounded by similar assemblies with one predicted for a $27.5-\mathrm{MWd} / \mathrm{kgU}, 5$-years-old spent fuel assembly using the new SFAT response function. Error bars are the measured data.

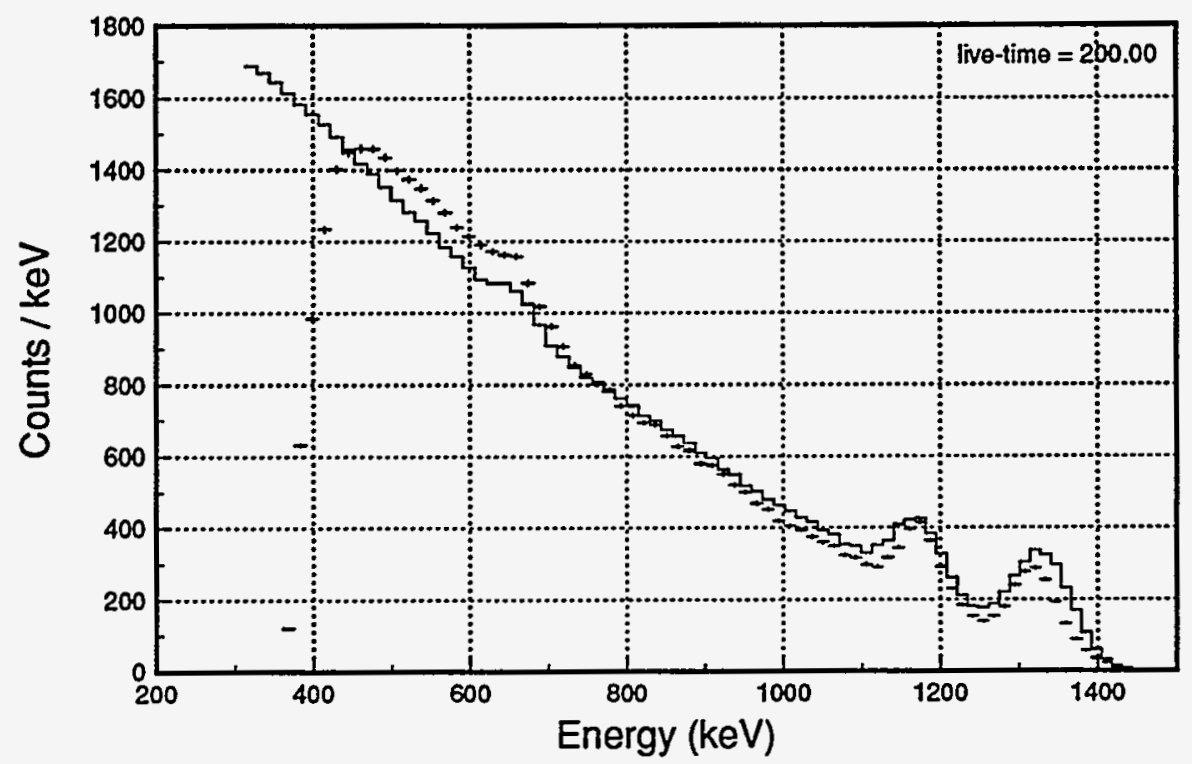

Figure 11. Comparison of a measured pulse-height spectrum from an 18-MWd/kgU, 8-years-old spent fuel assembly surrounded by similar assemblies with one predicted for a $27.5 \mathrm{MWd} / \mathrm{kgU}, 10$-years-old spent fuel assembly using the new SFAT response function. Error bars are the measured data. 


\section{Conclusions}

The new SFAT is greatly improved in performance over the original instrument. The original device generally required long count times to obtain an acceptable spectrum and was unable to detect ${ }^{137} \mathrm{Cs}$ from a long-cooled target assembly in the presence of short-cooled background assemblies. Measurements show the modified SFAT is able to obtain an acceptable spectrum in 200 seconds or less, and does detect ${ }^{137} \mathrm{Cs}$ from long-cooled target assemblies in the presence of short-cooled background assemblies. In some measurements with the new instrument the ${ }^{137} \mathrm{Cs}$ peak was visible after only 10 seconds of counting.

In addition to improving the characteristics of the SFAT, the modifications incorporated in the new instrument improve the operation of the device. The addition of an ultrasonic positioning system to the SFAT is an example to an operational component change. This positioning system improves repeatability of measurements, accuracy of positioning, and speed of operation. The repeatability allows double checking of measurements. The accuracy of positioning ensures optimum peak detection in all cases where a fuel channel is present; although, in cases where a fuel channel is not present some uncertainty in positioning accuracy remains. The spent fuel rack at KPA-Store is built to hold a BWR assembly with the fuel channel attached. When the fuel channel is removed, the "bare" assembly has room to lean. With the fuel assembly leaning, the top handle surface is not horizontal and the reflected sound waves from the ultrasonic positioning device are not moving exactly vertically. When the position is sensed from a non-horizontal surface the positioning device is not directly above the sensed surface, leading to uncertainty in the positioning. Improvement in the speed of operation allows the modified SFAT to perform a measurement in approximately 5 minutes per assembly, including movement to the next assembly.

Numerous changes were recommended for improving the original SFAT on the basis of radiation transport calculations. Predictions of the performance of the modified SFAT, obtained prior to the fabrication and testing of the device, compare favorably with the measurements. Thus these calculations saved expensive and time-consuming fabrication and testing of changes in the instrument in a trial-and-error design process. Radiation transport calculations have been shown to be an effective method of examining the relative merits of different design alternatives. 


\section{Acknowledgments}

Several individuals provided invaluable assistance in this effort. Rolf Arlt of the IAEA Department of Safeguards (Division of Development and Technical Support) spent many hours guiding the development and study of the SFAT. Matti Tarvainen of STUK led the development effort on the Finnish side of this project. Antero Tiitta of the VTT Reactor Laboratory provided indispensable help in making measurements and providing technical advice. In addition, TVO Power Company and its personnel gave unselfishly of their time and budget to ensure the success of the entire SFAT project. Specific mention of Ms. K. Saraparanta as the TVO point of contact, Mr. A Kaakinen for helping with TVO operational rules, and the fuel handling personnel is warranted. On the United States side of the effort, Cecil Sonnier provided essential aid in overcoming the administrative hurdles. In addition, the authors gratefully acknowledge the International Safeguards Project Office personnel and the U.S. State Department personnel for funding and assisting in the project. 


\section{References}

'Stephen A. Dupree and Thomas W. Laub, Radiation Source and Detector Response Modeling for Optimization of the Spent Fuel Attribute Tester, ISPO-352, Sandia National Laboratories, Albuquerque, New Mexico, USA, April 1993.

${ }^{2}$ Thomas W. Laub and Stephen A. Dupree, Optimization of the Spent Fuel Attribute Tester Using Radiation Transport Calculations, ISPO-353, Sandia National Laboratories, Albuquerque, New Mexico, USA, April 1993.

${ }^{3} \mathrm{M}$. Tarvainen, M Paakkunainen, A. Tiitta, K. Saraparanta, BWR SFAT, gross defect verification of spent BWR fuel; Final report on Task FIN A563 on the Finnish Support Programme to IAEA Safeguards, STUK-YTO-TR 72, Finnish Centre for Radiation and Nuclear Safety, Helsinki, Finland, April 1994.

${ }^{4}$ A. Tiitta, K. Kaita, and M. Tarvainen, SFAT geometry verification measurements at the TVO KPA-STORE, Interim report on Task FIN A563 of the Finnish Support Programme to IAEA Safeguards, STUK-YTO-TR 55, Finnish Centre for Radiation and Nuclear Safety, Helsinki, Finland, July 1993.

${ }^{5} \mathrm{~J}$ aakko Tikkinen and Matti Tarvainen (Ed.), Technical Exercise and Demonstration of the Spent Fuel Attribute Tester at the TVO NPS in Finland, 19.-23.3.1990, STUK-YTO-TR 27, Finnish Centre for Radiation and Nuclear Safety, Helsinki, Finland, May 1991.

${ }^{\circ}$ Dean J. Mitchell, Howard M. Sanger, and Keith W. Marlow, Gamma-Ray Response Functions for Scintillation and Semiconductor Detectors, Nucl. Instr. and Meth. A276 (1989) 547. 


\section{Ann Reisman \\ International Safeguards Project Office \\ Brookhaven National Laboratory \\ Building 475B \\ Upton, NY 11973}

$5 \quad$ Rolf Arlt

International Atomic Energy Agency

SGDID

Wagramerstrasse 5

PO Box 100

A-1400 Vienna, Austria

1 Matti Tarvainen

Finnish Centre for Radiation and Nuclear Safety

PO Box 14

FIN-00881

Helsinki, Finland

1 Antero Tiitta

Technical Research Centre of Finland

Physics Building (Otakaari 3 A, Espoo)

PO Box 1404

FIN-02044

VTT, Finland

4 MS 0571 Thomas W. Laub, 5914

5 MS 0567 Cecil Sonnier, 9208

1 MS 9018 Central Technical Files, 8523-2

5 MS 0899 Technical Library, 13414

1 MS 0619 Technical Publications, 12613

2 MS 0100 Document Processing, 7613-2

For DOE/OSTI 